\title{
A Design of Interface Model Based on HART Protocol
}

\author{
Lin Xiaoning \\ Department of Information Engineering \\ JIANGSU Radio and TV University \\ Nanjing, China
}

\begin{abstract}
A communication interface model based on HART protocol is designed in this paper. The definition of hardware interface and the implementation of software modules are presented in detail. According to the model, the development period of field communication system can be shortened to some extent. An example is introduced based on HART protocol in the end.
\end{abstract} Model

Keywords -HART Protocol, Field Bus, HT3012, Interface

\section{INTRODUCTION}

The technology of the digital control has been popularized and applied in industrial manufacturing process continuously, which puts forward more requirements for signal collection, transmission and data transform. The International Electrotechnical Commission (IEC), American instrumentation institute standards implementation committee (ISA 'S SP50) and others for the integration of field instruments system structure successively put forward the idea of field bus (field bus), which is to use digital signals to replace 4 to $20 \mathrm{~mA}$ analog signals.

HART (highway addressable remote transducer) communication protocol is raised by the American Rosemount company first, mainly for the digital communication of system and meter in the intelligent scene as a transitional international standard, now including $\mathrm{ABB}$, E\&H Smar etc ,more than 70 companies involved in this agreement.

HART agreement keeps the industrial standard of 4 to $20 \mathrm{~mA}$ analog signal, and realizes the function of digital signal transmission. At present it has been widely received and used and has become a kind of real industrial standards in the global scope. More and more industrial field equipment adopts HART interface to realize its additional function. For example Huang Han [1] applied the HART interface to the design of intelligent temperature transmitter. Chen Qiang [2] applied to design pressure transmitter protocol. Liao Wei [3] uses this protocol to allocate controller in various valve.

This paper using the HT3012 [4] chip of Smar company established a communication interface model corresponding with HART agreement. Based on this model, it can quickly develop field communication products that meet HART protocols.

\section{THE PRINCIPLE OF THE COMMUNICATION PROTOCOL}

HART agreement [5] developed on the basis of Bell 202 standard communications, using Frequency- Shift Keying (FSK) technology to change digital signal into audio signal, then adding to the current loop of 4 to $20 \mathrm{~mA}$ between the field devices and main control room to realize the digital signal communication.

HART protocol regulates: when current loop of 4 to $20 \mathrm{~mA}$ is superimposed frequency for $1200 \mathrm{~Hz}$ sinusoidal signal, it says logic "1", while $2200 \mathrm{~Hz}$ says logic " 0 ". Digital FSK signal phase of consecutive and the mean value of sine signal is zero, so it is no impact on 4 to $20 \mathrm{~mA}$ of current ring. In the premise of allowing digital signal not to interfere with analog signal, it can transmit in current ring of 4 to $20 \mathrm{~mA}$. The rate of transmission is $1200 \mathrm{Bit} / \mathrm{s}$, as is showed in Figure 1.

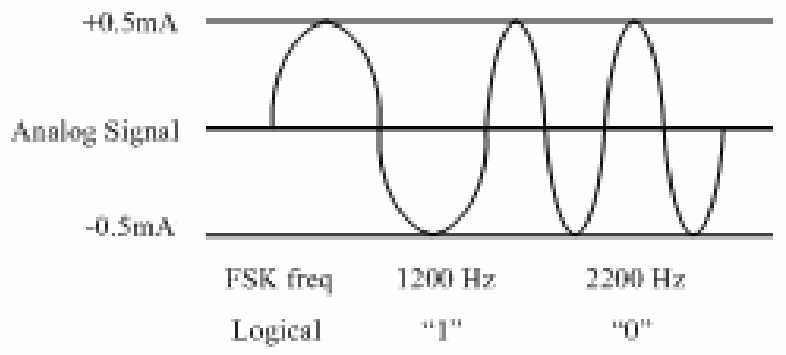

Figure 1 (a) digital signal code (Simultaneously analog and digital communication)

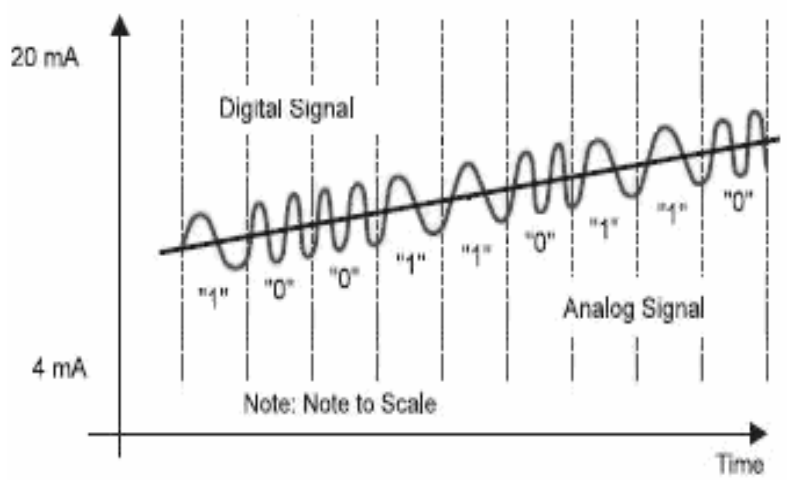

Figure 1 (b) HART digital signal superimposed on 4 to $20 \mathrm{~mA}$ analog signal 


\section{THE COMMUNICATION INTERFACE BASED}

\section{ON HART PROTOCOL}

\section{A. Hardware Interface}

The author chooses HT3012 to realize physical layer of HART protocol. HT3012 is one of HART communication chip launched by Smar company compatibling with communication standard of Bell 202. It integrates HART modems, LCD controller, D/A converter and a floating point arithmetic coprocessor, which is characteristics of low power consumption, low cost and high performance. Because of its high integration, it can be simplified circuit design and shorten the development cycle. Figure 2 shows the module chart of HT3012.

Integrated HT2012 modems in HT3012 chip can complete digital communication function of site equipment and control room; In addition, HT3012 also provides a 15 bits D/A converter, the accuracy of transformation is $0.5 \mathrm{uA} / \mathrm{bit}$, conversion pw2, pw1, results of the pw0 stacked output. To meet the requirements of the analog signal control, we use the current loop output.

HART signal is $1200 \mathrm{~Hz}$ or with $2200 \mathrm{~Hz}$ phase continuous sine wave, and HT3012 expressed in the integration of the HT2012 Modem receives input and output of the signals have a square wave, so HART signal HT2012 modulation and demodulation in enter when output of a band pass filter and respectively need orthopedics, and need to level conversion.

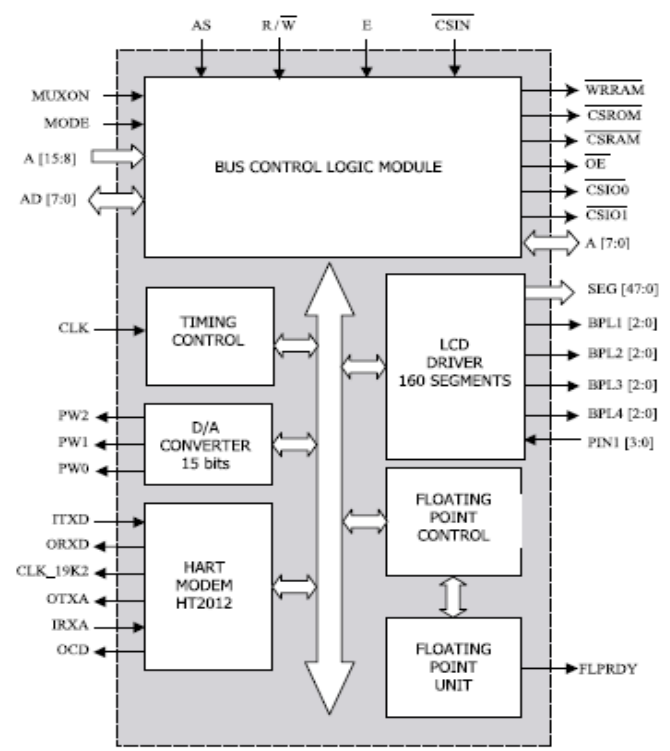

Figure 2. The Module Chart of HT3012

HART signal is expressed by $1200 \mathrm{~Hz}$ or $2200 \mathrm{~Hz}$ with phase continuous sine wave, while HT2012 Modem integrated in the HT3012 receives input and output of the signals both are square wave, so HART signal HT2012 modulation and demodulation, when output ,respectively need band pass filter and orthopedics, and need to convert level.
This paper uses band-pass filter circuit (Figure 3) to filter out 4 to $20 \mathrm{~mA} \mathrm{DC}$ signal and changes amplitude of 0.5 $\mathrm{mA}$ sine wave signal (HART signal) into 0 to $5 \mathrm{v}$ squarewave, for HT2012 demodulation HART signal.

Figure 4 shows plastic circuit will put the pulse signals of HT3012 output change into phase continuous sine signals, and complete the transformation, and output to the current ring of the 4 to $20 \mathrm{~mA}$.

In addition to the modem of Smar company meet HART protocol standard, the Symbios loigic company also offer equally functional chip, such as SYM20C15. Besides the function of modem, it has the shaping circuit and band-pass filter circuit, which can simplify part of peripheral circuitry.

In the proposed model, HT3012 mainly complete the control of MCU, communications, data processing, and other functions. Depending on the specific application environment, the selection of MCU still need consider power consumption, functions, etc. The United States of TI company produces MSP430 microcontroller. It is 16 bits architecture with the characteristics of powerful, high integrated and low power dissipation integration. It still has various case and optional function. It is recommended to use. In addition to the HT3012 for Motorola HC11 series microcontroller provides special support. If the product is being designed by strict limits, it also can consider using HT4012, which integrated HC11 single-chip HT2012 Modem, LCD controller, D/A converter, and floating point arithmetic coprocessor. Figure 5 shows the diagram of HART communication hardware interface.

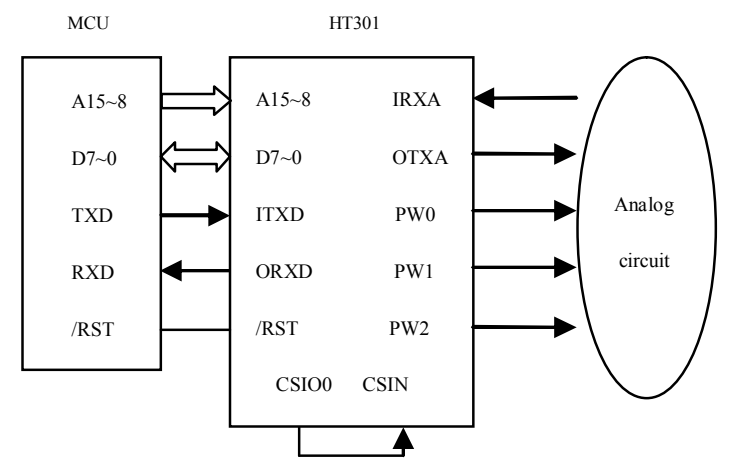

Figure 5. The diagram of HART communication hardware interface

\section{B. Software Realization}

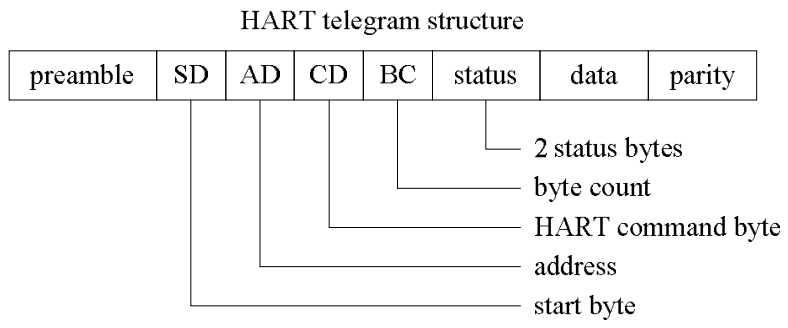

Figure 6. data frame format of HART communication

HART protocol based on the OSI reference model uses the 1,2, and 7 layers [6]. The first layer according with physical layer of the Bell 202 standard is responsible for the 
FSK signal. Transmission rate is $1200 \mathrm{Bit} / \mathrm{s}$. The second is the data link layer, also called protocol layer, data frame format and data communications procedures. Its frame format is described in Figure 6 . The longest is 25 bytes and regulate way mainly for communication mode. For application layer, layer 7 stipulates the content of HART communication model, divided into three types. respectively: general commands, applicable for all the instruments according with HART agreement, mainly including read identifier, read the original variables, such as read current command ects; ordinary command, suitable for most according with HART agreement, mainly including the command of read flow meter, temperature, quality, density and so on.; special orders, the specific equipment fabrication, if choose sensor command, read PID initialization state command, write PID parameters command, etc.

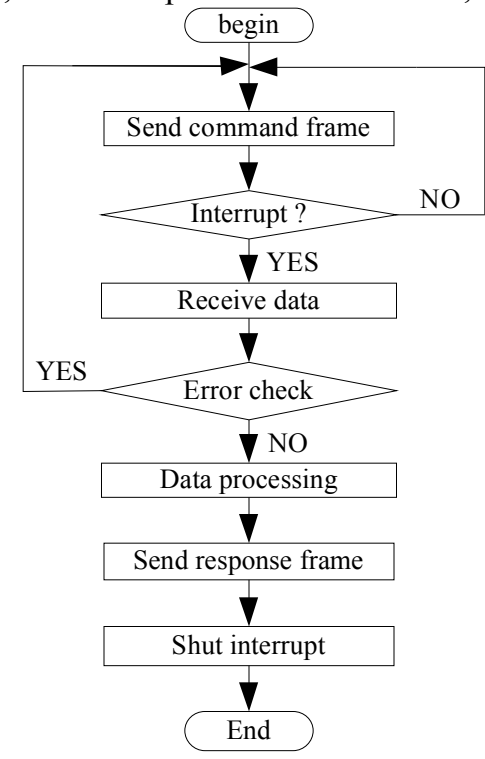

Figure 7. The Flow Chart of HART Communication Software

HART communication software in the essence realizes the function of software of data link layer and application layer in the HART protocol. This model carries out a master-slave communication program which only host asks only response from the machine. The system uses the serial port for program sending and receiving. First, the machine sends command frame through a serial port interrupt, then begin to receive orders from the machine frame. When receiving finished, it carries on data validation, if correct, microprocessor is for the data processing, otherwise says an error, and inform host retransmission data. Finally send end and response frame complete a command communication. Figure 7 shows the chart of specific software flow.

\section{APPLICATIONG EXAMPLES}

The author applied this model to a handwritten of being designed based on HART protocol. Based on this model it can be applied to this handwritten if modified case by case, and complete intelligent locator (with HART interface) or main control room for the function of digital communication, But it also increased the keyboard and LCD display, providing a friendly human-machine interface and operability. Communication, handwritten device, or main control room are as main equipment and field devices (locator) as slave equipment.

According to this model the article mentioned, adopts MSP430F149 as a controller, chooses Smar company HT3012 as HART signal modems (because Smar company the HT series modem with low consumption, become preferred chip that HART Foundation (HCF: HART Communication Foundation) recommended ). In order to reduce power consumption and the four units for HT3012 provide appropriate clock, choose the $1.8432 \mathrm{M}$ crystals source, so the $460.8 \mathrm{~K}$ clock model produced by HT3012 internal clock according to four points frequency is used by modems, but also assure other modules in the right job running frequency. Ensure the consistency of the system bus, microprocessor and HT3012 using the same reset source. Serial communication is between Microprocessor and HT3012.According to plastic and band-pass filter circuit, HT3012 send and receive audio signal of the current ring of 4 to $20 \mathrm{~mA}$ and communicate with peripheral circuit. Those who have HART interface can filter out the equipment on the current loop, and hand the processor HART signal to handle. No HART interface on-site equipment can also receive the current of 4 to $20 \mathrm{~mA}$ sent by the master, in order to reach mixed communication of digital signal and analog signals.

The diagram of hardware of hand hold device is shown in Figure 8. According to the figure, we can know that connect MCU and HART protocol demodulation chip through a serial port to realize the data and control information communication. It is namely that $\mathrm{MCU}$ is host and HT3012 is slave machine, thus output meets the requirement of $4 \sim 20 \mathrm{~mA}$ current of HART protocol and realize the communications between field devices.

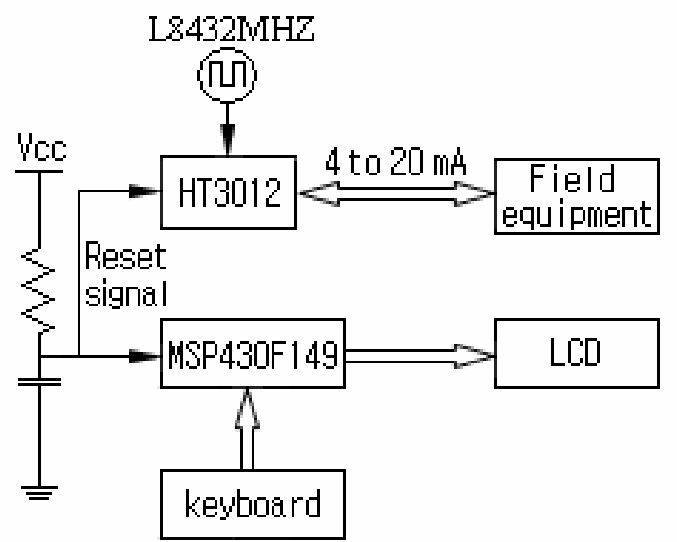

Figure 8. The Source Figure of Hand Hold Device's Hardware

\section{CONCLUSION}

The model in this paper has wide generalization. Everything in line with HART protocol field devices, intelligent transmitter, the original site equipment digital transformation can be used, and can shorten the development cycle. HART protocol, although be a 
transitional agreement, but according to the forecast of HART foundation, HART protocol can extend the cycle of more than five years. AS China's current situation is concerned, its life cycle will also based on this extended 20 years or so. That is, in the future for a very long time, the product of HART protocol still has wide market. Therefore the author thinks that it is very signification on the basis of the model to establish the development and design for promotion and application of field bus and it is worthwhile to costs energy.

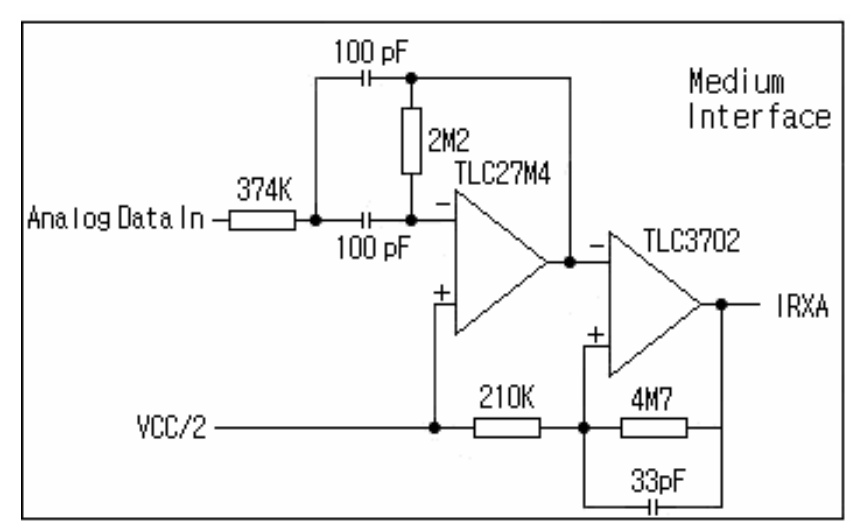

Figure 3. Diagram of Band-pass filter circuit

\section{REFERENCES}

[1] Huang Han. The design of intelligent temperature transmitter based on the HART protocol. 2010.

[2] Chen Qiang. The design of intelligent pressure transmitter based on HART protocol. Application of Electronic Technique. 2006.03.

[3] Liao Wei. The design and development of the system of intelligent positioning valve control 2009 .

[4] Smar Research Corporation, HT3012 Datasheet DS082000. 11.2000.

[5] HART Communication Foundation, HART Communication Protocol Application Guide, 1999.

[6] Smar Research Corporation, HART Communication. 2000.

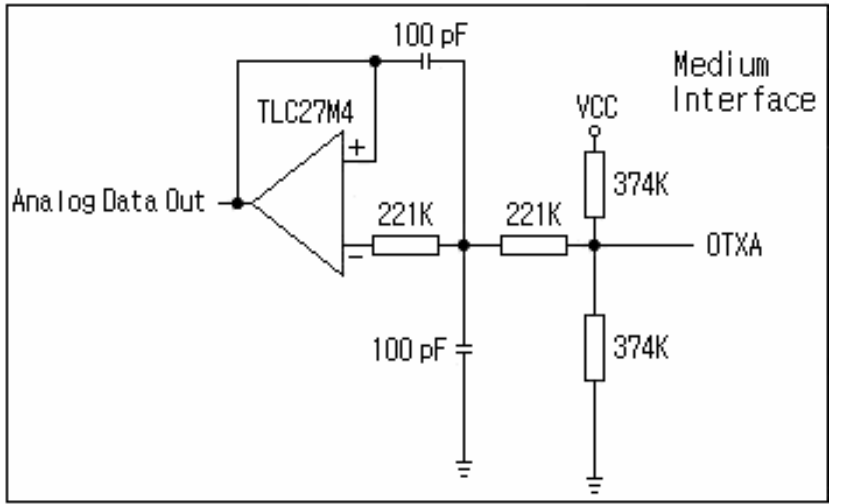

Figure 4 Output shaping circuit 